\title{
Study on Effect of Ultrasonic Vibration on Grinding Force and Surface Quality in Ultrasonic Assisted Micro End Grinding of Silica Glass
}

\author{
Zhang Jianhua, Zhao Yan, Zhang Shuo, Tian Fuqiang, Guo Lanshen, and Dai Ruizhen \\ School of Mechanical Engineering, Hebei University of Technology, Guangrongdao Street, Hongqiao, Tianjin 300130, China \\ Correspondence should be addressed to Zhang Jianhua; jhzhang@hebut.edu.cn
}

Received 28 February 2014; Revised 20 May 2014; Accepted 11 June 2014; Published 8 July 2014

Academic Editor: Mohammad Elahinia

Copyright (C) 2014 Zhang Jianhua et al. This is an open access article distributed under the Creative Commons Attribution License, which permits unrestricted use, distribution, and reproduction in any medium, provided the original work is properly cited.

\begin{abstract}
Ultrasonic vibration assisted micro end grinding (UAMEG) is a promising processing method for micro parts made of hard and brittle materials. First, the influence of ultrasonic assistance on the mechanism of this processing technology is theoretically analyzed. Then, in order to reveal the effects of ultrasonic vibration and grinding parameters on grinding forces and surface quality, contrast grinding tests of silica glass with and without ultrasonic assistance using micro radial electroplated diamond wheel are conducted. The grinding forces are measured using a three-component dynamometer. The surface characteristics are detected using the scanning electron microscope. The experiment results demonstrate that grinding forces are significantly reduced by introducing ultrasonic vibration into conventional micro end grinding (CMEG) of silica glass; ultrasonic assistance causes inhibiting effect on variation percentages of tangential grinding force with grinding parameters; ductile machining is easier to be achieved and surface quality is obviously improved due to ultrasonic assistance in UAMEG. Therefore, larger grinding depth and feed rate adopted in UAMEG can lead to the improvement of removal rate and machining efficiency compared with CMEG.
\end{abstract}

\section{Introduction}

Expanding requirements of microproducts with features and structures at microscale and nanoscale, such as micro optical system, micro robot, micro motor, and fuel injection nozzle, presents stimulation and challenges to micromachining technology $[1,2]$. Machining of micro parts made from nonferrous metals and other materials, which are not difficult to machine, can be reliably achieved by microturning, micromilling, microdrilling, and so forth [2]. However, there are only limited methods existing for the process of 3D micro components of hard and brittle materials. Microgrinding is one of the most promising processing technologies in this field. Ramesh et al. [3] conducted high-table-reversal-speed microgrinding tests on different hard and brittle materials, in which fine slots with $0.1 \mathrm{~mm}$ width and high aspect ratio of 15 were produced. The lowest surface roughness obtained of $\mathrm{WC}, \mathrm{Al}_{2} \mathrm{O}_{3}$, and $\mathrm{BK} 7$ are $0.16 \mu \mathrm{m}, 0.32 \mu \mathrm{m}$, and $0.52 \mu \mathrm{m}$, respectively. The lowest average surface roughness of $12.97 \mathrm{~nm}$ was achieved in Rahman's experiment [4], in which microgrinding of BK7 glass was carried out using microEDM-fabricated PCD tool.

There are many challenges that lie in microgrinding. High grinding forces in microgrinding result in high heat generation and rapid microwheel wear $[3,5,6]$. In addition, according to nanoindentation testing, median crack will generate and grow inward in the material when the load exceeds the critical value $[7,8]$. It is always required to obtain fracture-free surface, on which damage due to fracture cracks should not be achieved on the final machined surface [9]. The experiments indicate that higher grinding force will lead to more residual crack on surface and subsurface. Therefore, in order to yield high surface integrity and surface accuracy in microgrinding, cutting depth and feed rate must be maintained in a quite low level to limit grinding force, which results in low removal rate and low efficiency.

It is indicated by previous research on ultrasonic vibration assisted machining (UVAM) that machining quality can be significantly improved by introducing ultrasonic vibration. Starting with the investigation of vibration assisted planning, 


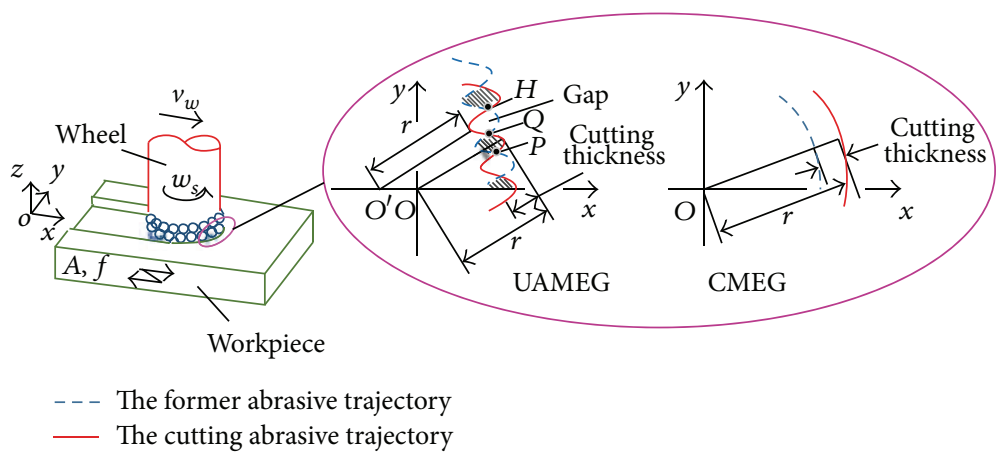

FIGURE 1: Machining process of UAMEG and conventional micro end grinding (CMEG).

Junichiro [10] initiated UVAM and conducted a series of experiments on it. Compared with traditional microgrinding, the cutting force was lowered by $30-50 \%$, the temperature in cutting area was lowered to the room temperature, and higher machining accuracy and lower workpiece surface roughness were achieved. Tawakoli et al. [11] conducted comparative experiments of ultrasonic assisted dry grinding and conventional dry grinding of $42 \mathrm{CrMo} 4$, which demonstrated considerable advantages of UVAM: up to $60 \%$ reduction of normal grinding force and significant improvement on the $R z$ parameter. Similar experiments were conducted on 100Cr6 [12], and the results indicated that the aided ultrasonic vibration considerably eliminated the thermal damage of workpiece surface and subsurface, increased the $G$-ratio, and reduced the grinding forces (up to $60-70 \%$ of normal grinding forces and up to $30-50 \%$ of tangential grinding forces). Akbari et al. [13] investigated the ultrasonic vibration effects on grinding process of alumina ceramic by experiments. The tests' results also indicated significant improvements: surface roughness improved by $8 \%$, total grinding force reduced by up to about $22 \%$, and workpiece fracture strength increased by approximately $10 \%$ on average. Therefore, UAMEG is treated to be a promising method to improve conventional microgrinding of microparts made of hard and brittle materials. However, research on the mechanism of this new processing method has not been reported so far.

In this paper, the influence of ultrasonic assistance on the mechanism of this processing technology is theoretically analyzed. UAMEG is applied to silica glass for the first time on a manual developed machine tool to experimentally study the mechanism of grinding forces and surface characteristics. Grinding forces are measured by a three-component force dynamometer unit and the surfaces are detected using scanning electron microscope (SEM).

\section{Mechanism Analysis of UAMEG}

2.1. Machining Process of UAMEG. The machining process of UAMEG can be seen in Figure 1. The precision feed of grinding wheel $v_{w}$ is in the direction of $x$-axis, along which the workpiece operates simple harmonic motion with small amplitude $A$ and high frequency $f$ (ultrasonic vibration). The grinding wheel rotates at high speed $\omega_{s}$ around the $z$-axis, which orients in cutting depth direction.
From Figure 1, it can be seen that exterior margin abrasives on the grinding wheel end face firstly cut into the unmachined material, which leads to shearing-forming chips or brittle-fracture chips (here defined as the first grinding zone); inner margin abrasives only encounter the machined material, which mainly lead to sliding, ploughing, and repeatedly ironing the machined material surface generated by the former abrasives due to the spring back of material (here defined as the second grinding zone). Therefore, the cutting thickness of exterior abrasives is much larger than cutting thickness of inner abrasives. So, fracture cracks are more likely to generate in the first grinding zone. In other words, if ductile grinding is achieved in the first grinding zone, final machined surface free of cracks can be obtained.

In Figure 1, the dashed curve refers to the trajectory of the former abrasive, which represents the profile of the unmachined region material. The solid curve is the trajectory of the cutting abrasive. In CMEG, the cutting abrasive continuously cuts the unmachined material. However, the cutting mechanism is different in UAMEG. When the solid curve moves to the right of the dashed curve, it indicates that the cutting abrasive cuts into the unmachined material, as from point $P$ to $Q$. When the solid curve moves to the left of the dashed curve, as from point $Q$ to $H$, the cutting abrasive withdraws from unmachined material region. There will be a gap between the cutting abrasive rake face and the unmachined material. Then, a new cutting cycle commences from point $H$. As this cutting cycle circulated at ultrasonic frequency, intermittent cutting is achieved in UAMEG.

2.2. Instantaneous Abrasive Cutting Thickness in UAMEG. In the present paper, the instantaneous abrasive cutting thickness $(h)$ is defined as the distance between trajectories of the cutting abrasive and the former abrasive in the direction parallel to the surface. Real abrasive cutting thickness is determined by the trajectories of several adjacent abrasives. But considering the feasibility of modeling and gradual wane of the influence of the abrasives increasingly distant from the cutting abrasive, only two adjacent abrasives are taken into account in this work. The geometrical schematic of instantaneous abrasive cutting thickness according to the trajectories of the two adjacent abrasives is shown in Figure 2 and is mathematically modeled in this section. The modeling is based on the following hypothesis: abrasives are well 


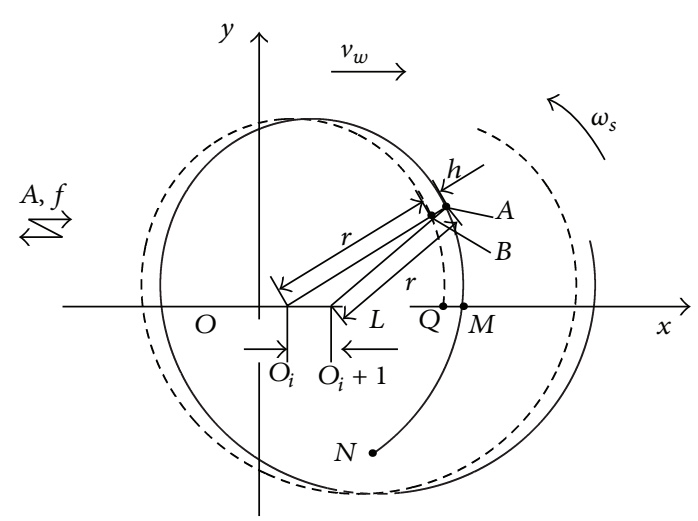

Figure 2: Geometrical schematic of instantaneous abrasive cutting thickness.

distributed with uniform size; deformation and run out of the wheel are negligible; the wheel end face is parallel to workpiece surface; ultrasonic amplitude and frequency keep steady in machining process.

The time when the former abrasive (here defined as the $(i+1)$ th abrasive) moves to point $Q$ and the cutting abrasive (here defined as the $i$ th abrasive) moves to point $N$ is defined as start time. $t_{B}$ is defined as the time when the $i$ th abrasive moves to point $B\left(x_{t_{B}}, y_{t_{B}}\right)$ along the dashed line. At the same time, the center of the wheel moves to point $O_{i}$. Point $A\left(x_{t_{A}}\right.$, $\left.y_{t_{A}}\right)$ is the intersection of trajectory of the $(i+1)$ th abrasive and the extension line of $l_{B O_{i}}$. The $(i+1)$ th abrasive moves to point $A$ at $t_{A}$ and the center of the wheel moves to point $O_{i+1}$ at the same time.

Based on the principles of geometry, instantaneous abrasive cutting thickness of the $(i+1)$ th abrasive at $t_{A}$ can be expressed as follows:

$$
h_{i+1}^{t_{A}}=\sqrt{r^{2}+L^{2}-2 r L \cos \left[\omega_{s}\left(t_{A}-\Delta_{t}\right)\right]}-r,
$$

where $\Delta_{t}\left(\Delta_{t}=1 / m n\right)$ is defined as the time difference according to the phase difference of these two adjacent abrasives, which is equal to the time that the $(i+1)$ th abrasive moves from point $N$ to point $M, m$ is the quantity of all the abrasives in the most exterior margin of micro wheel end face, $n$ is spindle speed, and $L$ is the distance between $O_{i}$ and $O_{i+1}$. Consider

$$
L=x_{0_{i+1}}-x_{o_{i}},
$$

where $x_{O_{i}}^{t_{B}}$ and $x_{O_{i+1}}^{t_{A}}$ are the $x$ position of the wheel center at $t_{B}$ and $t_{A}$, respectively, which can be further expressed as follows:

$$
\begin{gathered}
x_{O_{i+1}}^{t_{A}}=v_{w} \cdot t_{A}+A \cdot \sin \left(\omega_{f} \cdot t_{A}\right), \\
x_{O_{i}}^{t_{B}}=v_{w} \cdot t_{B}+A \cdot \sin \left(\omega_{f} \cdot t_{B}\right) .
\end{gathered}
$$

Then, the line $l_{B O_{i}}$ can be given as follows:

$$
l_{B O_{i}}: y_{t_{B}}=\left(x_{t_{B}}-x_{O_{i}}^{t_{B}}\right) \tan \left(\omega_{s} \cdot t_{B}\right) .
$$

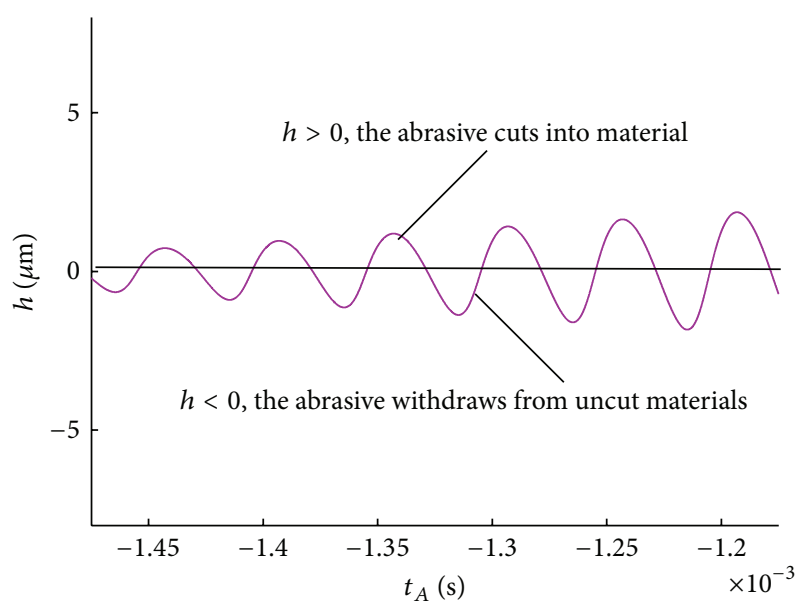

FIGURE 3: Instantaneous abrasive cutting thickness $(h)$ about $t$ during half a wheel rotating cycle.

TABLE 1: Simulation test parameters.

\begin{tabular}{lccccc}
\hline Parameter & $A(\mu \mathrm{m})$ & $f(\mathrm{kHz})$ & $n(\mathrm{r} / \mathrm{min})$ & $v_{w}(\mu \mathrm{m} / \mathrm{s})$ & $r(\mu \mathrm{m})$ \\
\hline Value & 3 & 20 & $9 \times 10^{3}$ & 300 & 1500 \\
\hline
\end{tabular}

The trajectory of the $(i+1)$ th abrasive in UAMEG can be expressed by

$$
\begin{gathered}
x_{i+1}=v_{w} t+r \cos \left(\omega_{s}\left(t-(i+1) \Delta_{t}\right)\right)+A \sin \left(\omega_{f} t\right) \\
y_{i+1}=r \sin \left(\omega_{s}\left(t-(i+1) \Delta_{t}\right)\right), \\
(i=0,1,2, \ldots),
\end{gathered}
$$

where $\omega_{f}\left(\omega_{f}=2 \pi f\right)$ is the angular frequency of ultrasonic vibration.

Because the point $A\left(x_{t_{A}}, y_{t_{A}}\right)$ is the intersection of the trajectory of the $(i+1)$ th abrasive and the extension line of $l_{B O_{i}}$, the following simultaneous equations system can be derived:

$$
\begin{gathered}
x_{t_{A}}=v_{w} \cdot t_{A}+r \cdot \cos \left(\omega_{s} \cdot\left(t_{A}-\Delta_{t}\right)\right)+A \cdot \sin \left(\omega_{f} \cdot t_{A}\right), \\
y_{t_{A}}=r \cdot \sin \left(\omega_{s} \cdot\left(t_{A}-\Delta_{t}\right)\right), \\
y_{t_{A}}=\left(x_{t_{A}}-x_{O_{i}}^{t_{B}}\right) \cdot \tan \left(\omega_{s} \cdot t_{B}\right) .
\end{gathered}
$$

The relationship between $t_{A}$ and $t_{B}$ can be obtained by solving (6) using MATLAB. Substitute it into (3), (2), and (1); then the final model of instantaneous abrasive cutting thickness is developed.

The simulation test is conducted using MATLAB under certain conditions in Table 1.

The simulation result of the instantaneous abrasive cutting thickness about $t_{A}$ in several ultrasonic cycles is shown in Figure 3. A positive $h$ value indicates that the abrasive cuts into unmachined materials. A negative $h$ value also indicates the abrasive withdraws from unmachined materials. It can be seen that $h$ repetitively oscillates as analogous sine wave 


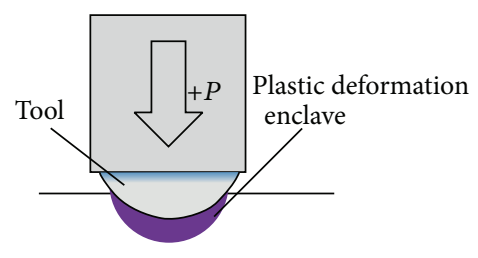

(a)

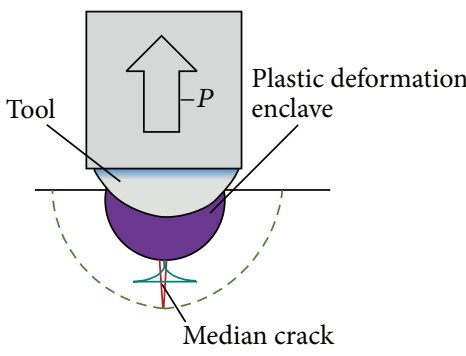

(c)

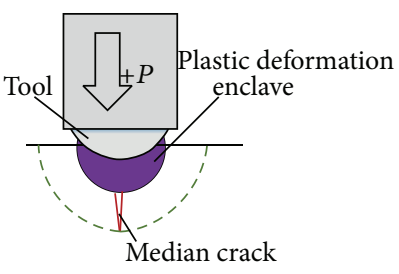

(b)

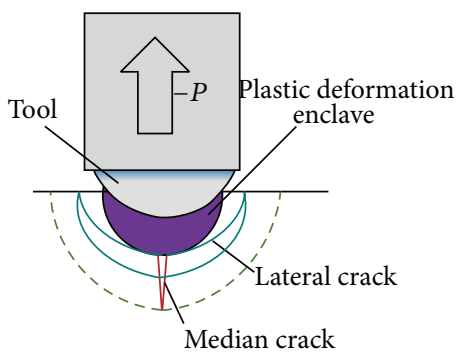

(d)

FIGURE 4: Indentation process of brittle materials.

at ultrasonic frequency, which indicates that intermittent cutting is achieved in UAMEG from the point of view of single abrasive, and the average value of $h$ is to be cut down significantly.

In the grinding process, single abrasive grinding force can be expressed as follows:

$$
F=K A_{(h)}^{\mu}, \quad(0<\mu<1),
$$

where $K$ is grinding force per unit grinding area, which depends on material properties, $A_{(h)}$ is the grinding crosssectional area, and $\mu$ is the coefficient of friction.

Grinding cross-sectional area $A_{(h)}$ is proportional to $h$; that is, $A_{(h)} \propto h$. Therefore, assisted ultrasonic vibration, which leads to low average value of $h$, is to cut down the average value of grinding cross-sectional area $A_{(h)}$.

Furthermore, when the intermittent cutting is achieved, the instantaneous gap, which will exist between the face of abrasive and unmachined material, is helpful to reduce the coefficient of friction $\mu$. In addition, the result of Clifton's research about the plate-impact tests for brittle materials demonstrates that the dynamic fracture toughness is less than $30 \%$ of the static fracture toughness. Therefore, considering the impact effect in UAMEG, the dynamic fracture toughness, which is favorable to decrease the value of $K$, should be considered in the grinding force model for single abrasive.

As a result, single abrasive grinding force and thus the whole wheel grinding force are to effectively decrease due to assisted ultrasonic vibration in UAMEG.

\subsection{Undeformed Chip Thickness and Ductile Machining in} $U A M E G$. The machining mechanism is greatly influenced by the ratio of the effective cutting edge radius of the tool to the undeformed chip thickness in micromachining. Because the edge radius of the abrasives tends to be in the same scale with the undeformed chip thickness, a small change in undeformed chip thickness significantly influences the grinding process [5]. This ratio predominantly defines the active material removal mechanism such as brittle-ductile transition. Therefore, the abrasive is assumed to be hemispheric to take into consideration low undeformed chip thickness in UAMEG. Then, ductile machining by UAMEG is analyzed in this section.

Indentation tests were conducted to investigate the plasticity of brittle material $[8,14]$. Crack initiation and growth during indentation process of brittle material are shown in Figure 4. As the indenter tip penetrates into the surface of the sample of brittle material under small load, the material exhibits elasticity with formation of plastically deformed zone in the form of a hemispheric enclave. The bottom of this plastic zone is conserved under high residual stresses. With the increase of the load, a crack called median crack is initiated from the bottom of plastic zone along the axial direction of the load. During unloading half cycle, the lateral crack is initiated, oriented in the lateral direction to the load axe. As unloading continues, lateral crack grows towards the surface.

Considering analogous sine waved instantaneous abrasive cutting thickness, crack initiation and growth during single abrasive cutting process in UAMEG can be interpreted as shown in Figure 5. When $h$ is negative, the abrasive withdraws from the uncut shoulder and only slides on the machined surface. As $h$ increasing the abrasive cuts gradually into uncut shoulder material, the material exhibits elasticity followed by formation of plastically deformed zone in the form of a hemispheric enclave. When the maximum undeformed chip thickness $\left(t_{\max }\right)$ exceeds the critical undeformed chip thickness (below which chips will not form), the abrasive removes the material via plastic deformation. At some $h$ values where $t_{\max }$ and cutting force are in excess of the critical values, median cracks initiate and grow with increasing $h$. As the abrasive passed, which is analogous to the unloading half cycle, the residual stresses beneath the plastic zone propagate lateral cracks. Then, the lateral cracks grow towards surface 


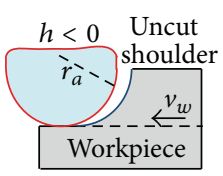

(a)

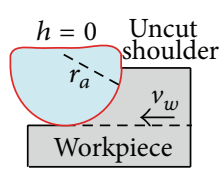

(b)

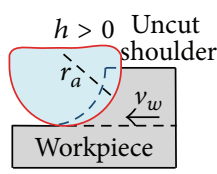

(c)

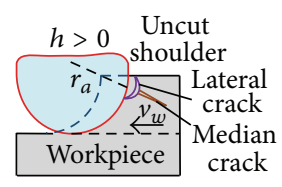

(d)

FIGURE 5: Abrasive cutting process under intermittent machining in UAMEG.

of uncut shoulder and thus a part of uncut shoulder material is to be removed via brittle pattern.

According to Arif et al.s [9] research, it is fair enough assumed that even if median cracks and lateral cracks are generated, the cracks can still get clear of the final machined surface under some certain conditions, as is shown in Figure 6.

Arif et al. [9] demonstrate that fracture of final machined surface is predominantly influenced by the median crack. The length of median crack is equal to seven times of the radius of lateral crack; that is, $C_{m}=7 C_{L}[15]$.

The critical condition that both of these two crack systems approach the final machined surface can be given as follows:

$$
\begin{gathered}
C_{m} \cdot \cos \theta=C_{L}, \\
\theta=\arccos \left(\frac{1}{7}\right)=81.79^{\circ} .
\end{gathered}
$$

As the $\theta$ range from 0 to $81.79^{\circ}$, depth of damage due to median crack remains more than damage depth due to radius of lateral crack. Beyond this limit of $\theta, C_{L}$ is too small to reach the final machined surface. Thus, if median cracks do not approach the final machined surface, ductile machining can be achieved.

From the geometry of Figure 6, critical condition, which obtains final fracture-free machined surface, can be written as follows:

$$
\begin{gathered}
C_{m} \cdot \cos \phi_{c}+r_{a} \cdot \cos \theta_{c}=r_{a}, \\
\left(r_{a}-t_{c}\right) \cdot \cos \phi_{c}=r_{a} \cos \theta_{c}, \\
r_{a}^{2}+h^{2}-2 \cdot r_{a} \cdot h_{c} \cdot \sin \theta_{c}=r_{a}-t_{c},
\end{gathered}
$$

where $t_{c}$ is the critical undeformed chip thickness for ductile brittle transition, $r_{a}$ is radius of the abrasive, and $h_{c}$ is the critical instantaneous abrasive cutting thickness for ductile grinding.

Then, substituting (8) into (9), $h_{c}$ can be expressed as follows:

$$
h_{c}=r_{a} \cdot \sin \theta_{c}-\sqrt{r_{a}^{2} \cdot\left(\sin ^{2} \theta_{c}-1\right)+\left(\frac{\cos \theta_{c} \cdot C_{m}}{1-\cos \theta_{c}}\right)^{2}} .
$$

It can be seen from (12) that the critical median crack length $C_{m}$ leads to a limit to the critical instantaneous abrasive cutting thickness $h_{c}$ under given abrasive radius $r_{a}$ and cutting speed. This defines the upper limit of material removal rate for ductile machining. Critical instantaneous abrasive cutting thickness increases with the decrease of critical median

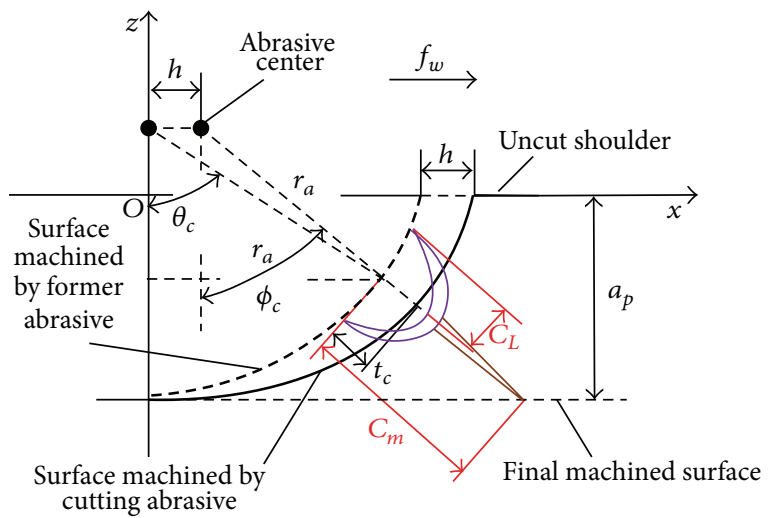

FIgURE 6: Geometry of critical undeformed chip thickness $\left(t_{c}\right)$ of ductile machining.

crack length. That means lower critical median crack length improves material removal rate under ductile machining.

From Lawn and Marshall's [8] research, the critical median crack length $C_{m}$ can be expressed as follows:

$$
C_{m}=\mu_{0}\left[\frac{K_{I C}^{2}}{H^{2}}\right]
$$

where $\mu_{0}$ is the geometrical constant which depends on material properties, $H$ is material hardness, and $K_{I C}$ is material static fracture toughness.

Assisted ultrasonic vibration will lead to high level of dynamic impact load between abrasives and workpiece material. In addition, as mentioned above, dynamic fracture toughness $K_{I D}$ reduces to less than $30 \%$ of $K_{I C}$ for brittle materials under impact load. Thus, critical median crack length $C_{m}$ is to be decreased due to the assisted ultrasonic vibration. In other words, ductile machining is easier to be achieved in UAMEG. Therefore, higher abrasive cutting thickness and thus higher grinding depth and feed rate, which can be allowed for ductile machining in UAMEG compared with CMEG, improve the material removal rate under the guarantee of high machining quality.

\section{Experimental Details}

3.1. Experimental Set-Up. The ultrasonic vibration assisted micro end grinding of silica glass is conducted on a manual developed machine tool, as is shown in Figure 7, which is built for the purpose of realizing three crucial motions in UAMEG: workpiece ultrasonic vibration, high speed grinding wheel rotation, and high-accuracy feed motion. 


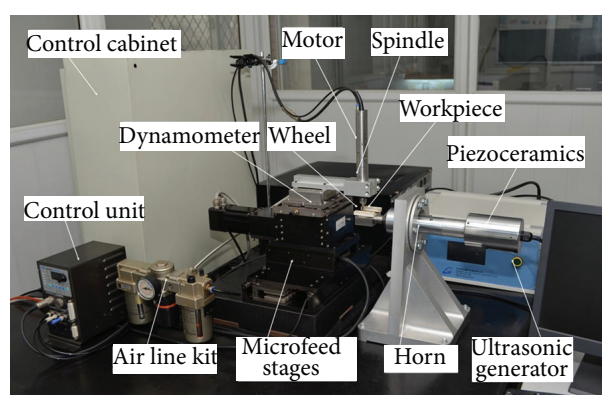

(a) The machine tool

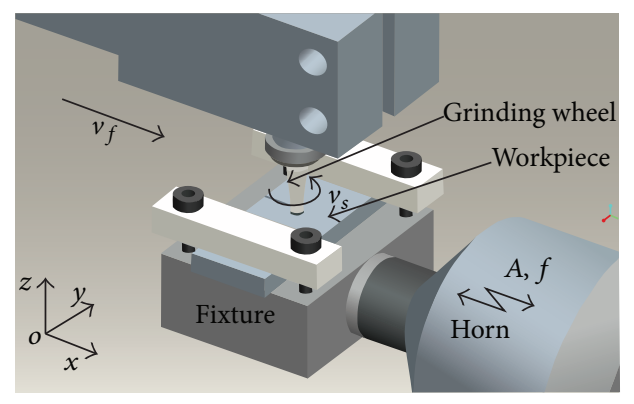

(b) Amplified drawings

FIGURE 7: Experimental set-up.

Ultrasonic vibration of the silica glass sample, which is actually reciprocation harmonic motion with high frequency and low amplitude, is created by a piezoelectric actuator with the input of sine voltage signal derived from an ultrasonic generator. The vibration amplitude is amplified by a specially designed acoustical waveguide booster to attain desirable vibration amplitude values on sample. The silica glass sample is adhered and fixed onto a fixture, which is designed to be the minimum dimension and weight to limit distortion of ultrasonic waveform and loss of ultrasonic energy. Ultrasonic vibration of the sample with tunable amplitudes (from 3 to $8.5 \mu \mathrm{m}$ ) at frequency $20 \mathrm{KHz}$ can be achieved by changing the input power from 0.2 to $0.8 \mathrm{~kW}$.

High-speed and reliable rotating motion of microdiamond grinding wheel is supported by a high-performance spindle system. The microelectroplated diamond grinding wheel (radius $1500 \mu \mathrm{m}$ ) is installed on a high speed spindle (up to $50000 \mathrm{rpm}$ ) with high spindle accuracy (within $1 \mu \mathrm{m}$ ).

High-accuracy micro feed motion is created by a triaxial micro feed system. It is assembled with two precision grade linear motor horizontal stages with position accuracy $3 \mu \mathrm{m}$ and bidirectional repeatability $\pm 0.4 \mu \mathrm{m}$ and a precision grade servo motor vertical stage resolution with accuracy $\pm 1 \mu \mathrm{m}$ and bidirectional repeatability $\pm 0.75 \mu \mathrm{m}$.

A three-component force dynamometer unit (Kistler 9256-C2) is used for the measurement of the grinding forces, as is shown in Figure 8. The grinding forces generated in grinding zone are to be converted into charge signal by the piezoelectric dynamometer. The multichannel charge amplifier receives the charge signal from the dynamometer and converts it into a proportional voltage. The built-in highpass filter is used to filter interference signal from spindle rotation. A data acquisition and analysis system (DynoWare) is used for data collection and display.

3.2. Experimental Conditions and Preparation. To investigate particularly and contrastively the influence of aided ultrasonic vibration and grinding parameters on variation tendency of grinding forces and surface characteristics, the single factor experiment is set up and the experimental grinding parameters are shown in Table 3 . The dimension of the silica glass sample is $50 \times 20 \times 3 \mathrm{~mm}$, and its material properties are shown in Table 2 . The radius and grain size

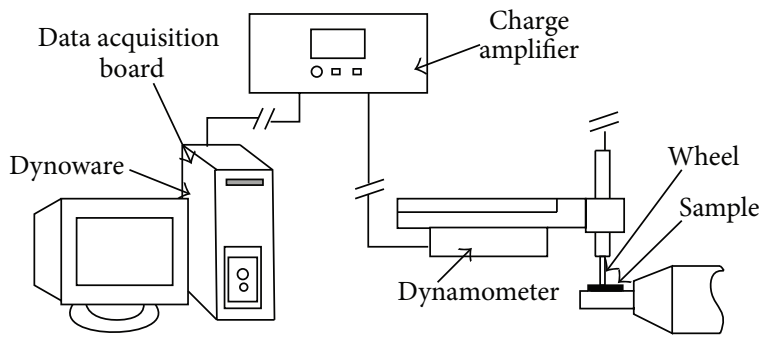

FIGURE 8: Schematic of force measurement instrument.

TABLE 2: Material properties of silica glass sample.

\begin{tabular}{lc}
\hline Property name & Value \\
\hline Hardness $(\mathrm{GPa})$ & 6.2 \\
Young modulus $(\mathrm{GPa})$ & $820 \times 10^{3}$ \\
Fracture toughness $\left(\mathrm{MPa} / \mathrm{m}^{1 / 2}\right)$ & 1.2 \\
\hline
\end{tabular}

of the electroplated diamond grinding wheel are $1.5 \mathrm{~mm}$ and 270 , respectively. To minimize the influence of parallelism error of wheel end face and sample surface, the experimental system is adjusted using a gradienter during assembling and clamping process, and repeated fine grinding is conducted on sample surface before every recorded test.

\section{Results and Discussion}

4.1. Influence of Ultrasonic Vibration and Grinding Parameters on Grinding Forces. Figure 9(a) shows the grinding forces in contrastive experiments with and without ultrasonic vibration under the grinding conditions of $n=1.8 \times 10^{4} \mathrm{r} / \mathrm{min}$, $a_{p}=2 \mu \mathrm{m}$, and $v_{w}=100 \mu \mathrm{m} / \mathrm{s} ; F_{n}, F_{t}$, and $F_{c}$ denote the normal, tangential, and cross feed directional grinding force, respectively. It can be seen that the normal grinding force and the tangential grinding force in experiments with ultrasonic vibration are much less than those in experiments without ultrasonic vibration. They reach the minimum values at ultrasonic amplitude of $7.5 \mu \mathrm{m}$ and then increase with ultrasonic amplitude increasing to $8.5 \mu \mathrm{m}$. The influence of ultrasonic assistance on cross feed direction is only minute.

The influences of grinding conditions on grinding forces in UAMEG are shown in Figures 9(b), 9(c), and 9(d). 


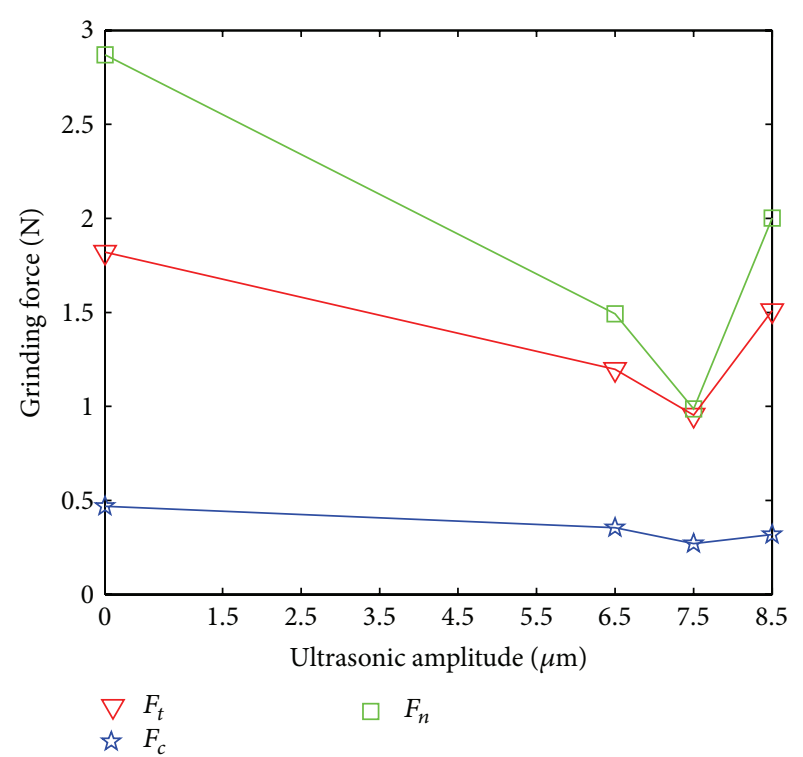

(a)

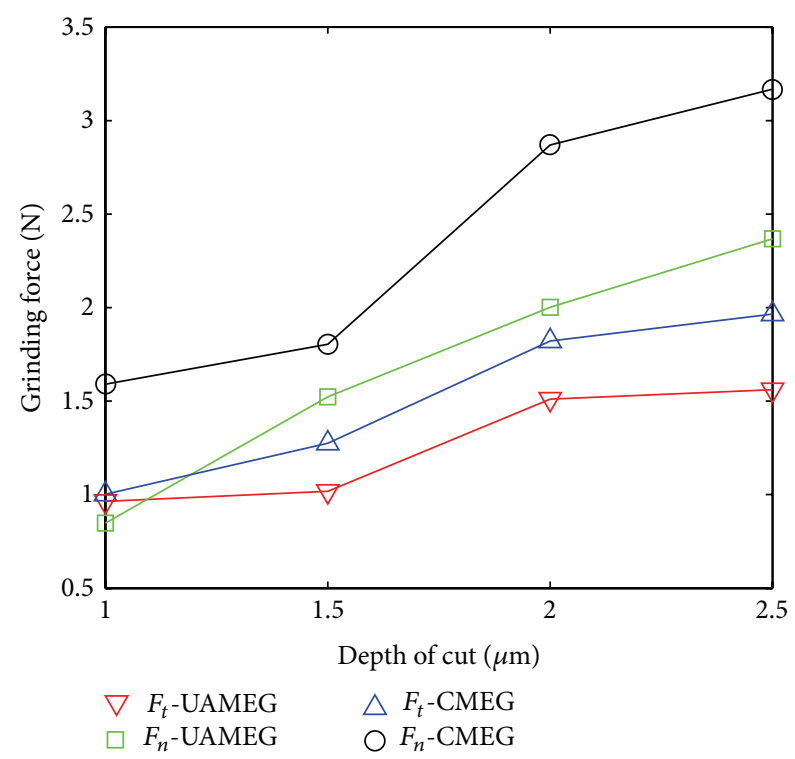

(c)

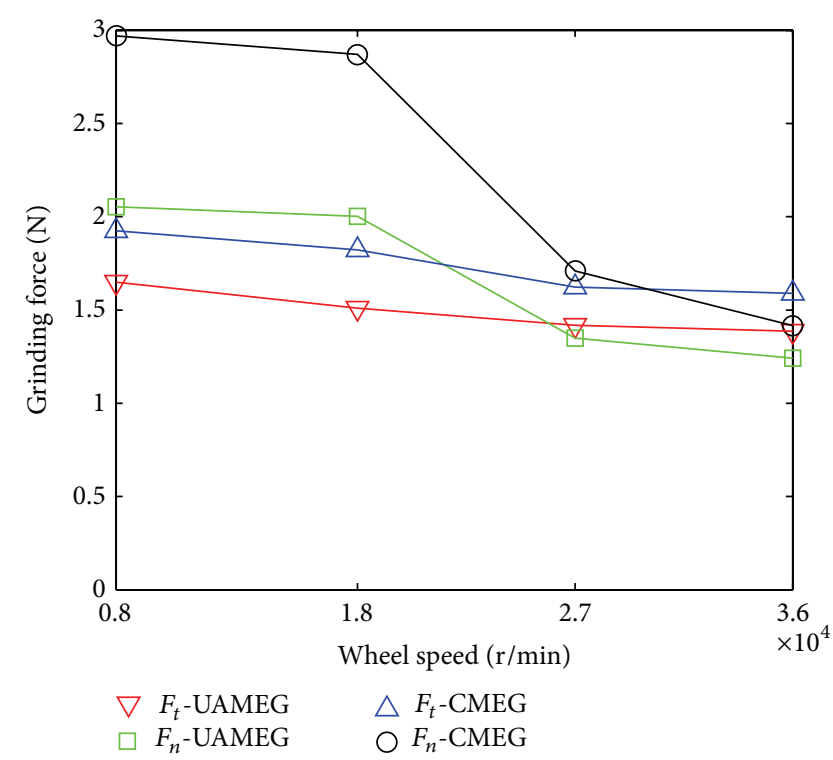

(b)

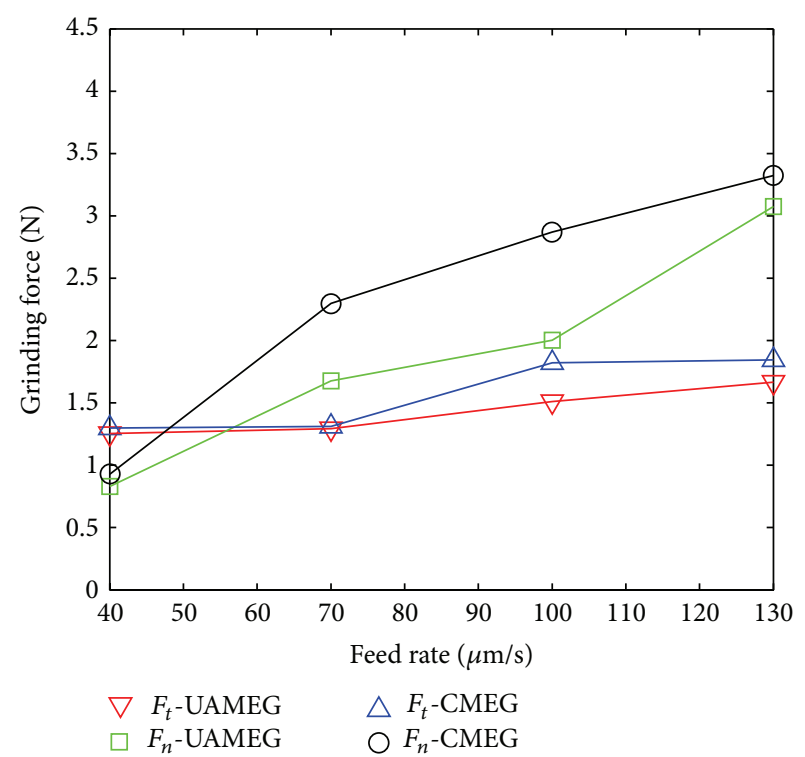

(d)

FIGURE 9: Effects of ultrasonic amplitude and grinding parameters on grinding forces. (a) Effects of ultrasonic amplitude $\left(v_{w}=100 \mu \mathrm{m} / \mathrm{s}\right.$, $\left.a_{p}=2 \mu \mathrm{m}, n=18000 \mathrm{r} / \mathrm{min}\right)$. (b) Effects of wheel speed $\left(v_{w}=100 \mu \mathrm{m} / \mathrm{s}, a_{p}=2 \mu \mathrm{m}, A=8.5 \mu \mathrm{m}\right)$. (c) Effects of depth of cut $\left(v_{w}=100 \mu \mathrm{m} / \mathrm{s}\right.$, $n=18000 \mathrm{r} / \mathrm{min}, A=8.5 \mu \mathrm{m})$. (d) Effects of wheel feed rate $\left(a_{p}=2 \mu \mathrm{m}, n=18000 \mathrm{r} / \mathrm{min}, A=8.5 \mu \mathrm{m}\right)$.

In both UAMEG and CMEG, the normal grinding force decreases rapidly, and the tangential grinding force decreases smoothly when wheel speed increases from $8000 \mathrm{r} / \mathrm{min}$ to $36000 \mathrm{r} / \mathrm{min}$. The normal grinding force increases with the increase of depth of cut and feed rate rapidly; meanwhile, the tangential grinding force increases rapidly with depth of cut but smoothly with feed rate.

It is indicated from Table 4 that the variation percentages of tangential grinding forces with the increase of wheel speed, depth of cut, and feed rate in UAMEG are smaller than those in CMEG. The variation percentages of normal grinding forces with the increase of wheel speed and feed rate in UAMEG are larger than those in CMEG. Meanwhile, the variation percentages with the increase of wheel speed in UAMEG are smaller than those in CMEG. It can be concluded that aided ultrasonic vibration weakens the effect of the increase of wheel speed on variation percentage of normal grinding force but strengthens the effect of the increase of depth of cut and feed rate. The aided ultrasonic vibration enhances the effect of the increase of all the three grinding parameters on variation tangential grinding force.

Considering the inhibiting effect of ultrasonic assistance on variation percentages of the tangential grinding force with increasing of grinding parameters, larger depth of cut and 
TABLE 3: Parameters of microgrinding experiment.

\begin{tabular}{lcccc}
\hline Ex. number & $A(\mu \mathrm{m})$ & $n(\mathrm{r} / \mathrm{min})$ & $a_{p}(\mu \mathrm{m})$ & $v_{w}(\mu \mathrm{m} / \mathrm{s})$ \\
\hline 1 & 0 & 18000 & 2 & 100 \\
2 & 6.5 & 18000 & 2 & 100 \\
3 & 7.5 & 18000 & 2 & 100 \\
4 & 8.5 & 18000 & 2 & 100 \\
5 & 8.5 & 8000 & 2 & 100 \\
6 & 8.5 & 27000 & 2 & 100 \\
7 & 8.5 & 36000 & 2 & 100 \\
8 & 8.5 & 18000 & 1.5 & 100 \\
9 & 8.5 & 18000 & 2.5 & 100 \\
10 & 8.5 & 18000 & 1 & 100 \\
11 & 8.5 & 18000 & 1 & 40 \\
12 & 8.5 & 18000 & 1 & 70 \\
13 & 8.5 & 18000 & 1 & 130 \\
14 & 0 & 8000 & 2 & 100 \\
15 & 0 & 27000 & 2 & 100 \\
16 & 0 & 36000 & 2 & 100 \\
17 & 0 & 18000 & 1.5 & 100 \\
18 & 0 & 18000 & 2.5 & 100 \\
19 & 0 & 18000 & 1 & 100 \\
20 & 0 & 18000 & 1 & 40 \\
21 & 0 & 18000 & 1 & 70 \\
22 & 0 & 18000 & 1 & 130 \\
\hline & & & &
\end{tabular}

TABLE 4: Variation percentages of the grinding forces with/without ultrasonic assistance.

\begin{tabular}{lccc}
\hline \multicolumn{2}{c}{ Ex. number } & \multicolumn{2}{c}{ Variation percentage (\%) } \\
& & UAMEG & CMEG \\
\hline \multirow{2}{*}{ Wheel speed } & $F_{n}$ & -39.6 & -52.3 \\
& $F_{t}$ & -15.9 & -17.4 \\
\hline \multirow{2}{*}{ Depth of cut } & $F_{n}$ & 179.0 & 99.2 \\
& $F_{t}$ & 61.9 & 96.2 \\
\hline \multirow{2}{*}{ Feed rate } & $F_{n}$ & 270.5 & 258.3 \\
& $F_{t}$ & 32.9 & 42.0 \\
\hline
\end{tabular}

feed rate can be adopted in UAMEG compared with CMEG, which is helpful to improve removal rate and machining efficiency. However, ultrasonic vibration contributes to negative action on variation percentage of normal grinding force with the increase of grinding parameters compared with CMEG.

\subsection{Influence of Ultrasonic Vibration and Grinding Parameters} on Machined Surface. It is very important to study the quality of machined surface to further investigate the effect of assisted ultrasonic vibration and grinding parameters on machining mechanism in UAMEG. Images of microtopography of the machined surfaces under six sets of conditions taken by SEM are shown in Figure 10.

In Figure 10(a), the darkness region represents complex fracture on the surface. It is indicative of brittle-regime removal and severe surface damage. It points to the fact that cracks penetrated into the final machined surface lead to complex fracture in CMEG under high instantaneous abrasive cutting thickness and undeformed chip thickness. Contrast result in UAMEG is shown in Figure 10(b). A squamous structure is formed on machined surface under ultrasonic assistance with amplitude of $6.5 \mu \mathrm{m}$, which indicates a complex process of brittle and ductile removal. It can be interpreted that intermittent cutting due to assisted ultrasonic vibration leads to the decrease of instantaneous abrasive cutting thickness and undeformed chip thickness. As is investigated above, instantaneous abrasive cutting thickness repetitively oscillates as analogous sine wave at ultrasonic frequency. When the instantaneous abrasive cutting thickness increases from zero, material is removed in the form of plastic deformation; meanwhile the plastic deformation accumulates and enlarges with the instantaneous abrasive cutting thickness increasing. When the maximum undeformed chip thickness is more than the critical value $t_{c}$, cracks initiate and grow. As the instantaneous abrasive cutting thickness exceeds the critical $h_{c}$ value determined by (12) and (13), cracks achieve to the final machined surface. However, surface damage and surface roughness are significantly improved due to ultrasonic assistance.

The comparison between the characteristics of surface in Figures 10(b), 10(c), and 10(d) shows the influence of ultrasonic amplitude on machined surface. It can be seen that when the ultrasonic amplitude increases from $6.5 \mu \mathrm{m}$ to $7.5 \mu \mathrm{m}$, there exists little evidence of fracture crack remaining on surface. It can be explained that ultrasonic effect becomes more significant with ultrasonic amplitude increasing. But when the ultrasonic amplitude increases to $8.5 \mu \mathrm{m}$, fracture cracks occurring again become even more severe than that in Figure 10(b), as shown in Figure 10(d). This may be due to the excessive impact power between the abrasive and materials when the ultrasonic amplitude increases to $8.5 \mu \mathrm{m}$.

When the grinding depth decreases from $2 \mu \mathrm{m}$ to $1 \mu \mathrm{m}$, as is shown in Figures 10(d) and 10(e), a squamous structure takes the place of fracture on machined surface. It indicates that more materials are removed in ductile region and the remaining fracture cracks are reduced with lower grinding depth.

Comparing Figures 10(d) and 10(f), it can be seen that machined surface is improved with the wheel speed increasing from $18000 \mathrm{r} / \mathrm{min}$ to $27000 \mathrm{r} / \mathrm{min}$. Obvious plastic ploughing grooves and trivial fractures are observed on the surface in Figure 10(f), which indicates that abrasive cutting thickness and undeformed chip thickness decline with the increase of wheel speed and thus brittle fracture is significantly reduced.

In conclusion, adding ultrasonic vibration can significantly improve the quality of machined surface due to intermittent cutting, which leads to the reduction of abrasive cutting thickness and undeformed chip thickness. But ultrasonic vibration with excessive amplitude is disadvantageous for surface quality. Low grinding depth and high wheel speed are beneficial to the machined surface.

\section{Conclusions}

In this paper, the promising processing method UAMEG for hard and brittle materials is researched. The effect of 


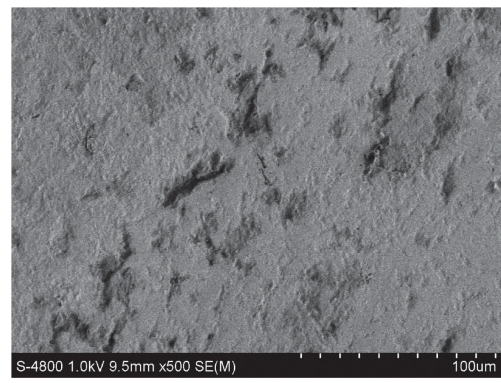

(a)

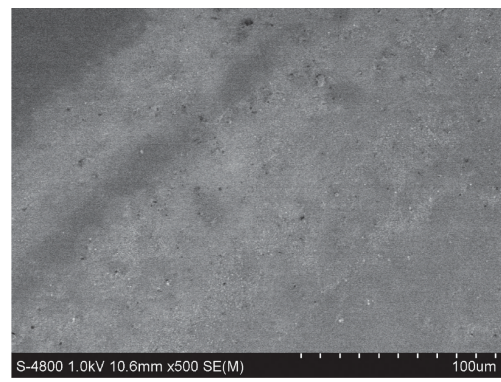

(c)

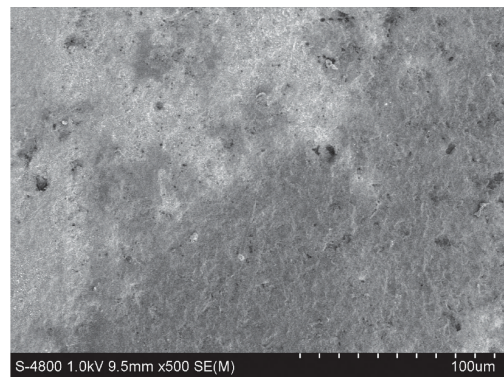

(e)

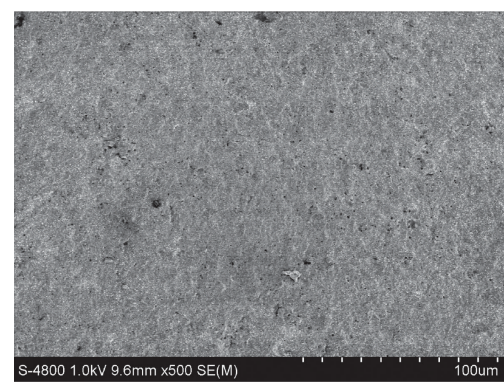

(b)

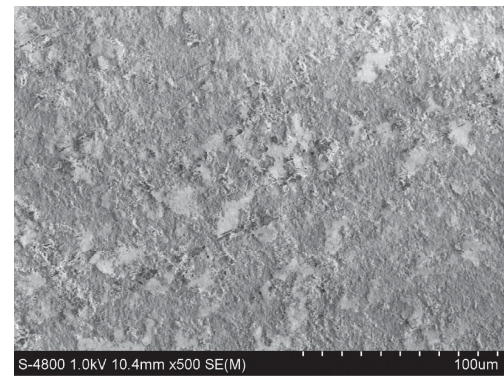

(d)

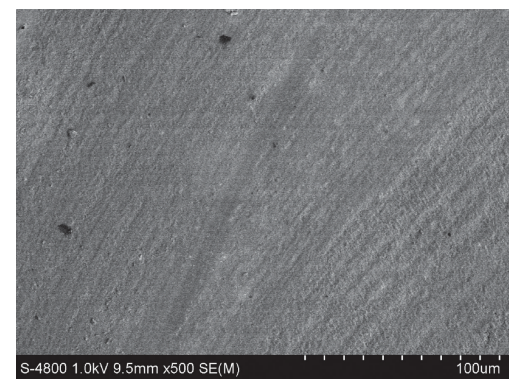

(f)

Figure 10: Surface machined at (a) $A=0 \mu \mathrm{m}, a_{p}=2 \mu \mathrm{m}, f_{w}=100 \mu \mathrm{m}, n=18000 \mathrm{r} / \mathrm{min}$; (b) $A=6.5 \mu \mathrm{m}, a_{p}=2 \mu \mathrm{m}, f_{w}=100 \mu \mathrm{m}$, $n=18000 \mathrm{r} / \mathrm{min}$; (c) $A=7.5 \mu \mathrm{m}, a_{p}=2 \mu \mathrm{m}, f_{w}=100 \mu \mathrm{m}, n=18000 \mathrm{r} / \mathrm{min}$; (d) $A=8.5 \mu \mathrm{m}, a_{p}=2 \mu \mathrm{m}, f_{w}=100 \mu \mathrm{m}, n=18000 \mathrm{r} / \mathrm{min}$; (e) $A=8.5 \mu \mathrm{m}, a_{p}=1 \mu \mathrm{m}, f_{w}=100 \mu \mathrm{m}, n=18000 \mathrm{r} / \mathrm{min}$; (f) $A=8.5 \mu \mathrm{m}, a_{p}=2 \mu \mathrm{m}, f_{w}=100 \mu \mathrm{m}, n=27000 \mathrm{r} / \mathrm{min}$.

ultrasonic assistance on grinding forces and surface characteristics is theoretically and experimentally studied. The following can be concluded from this study.

(1) Ultrasonic assistance changes the machining mechanism of micro end grinding from the point of view of instantaneous abrasive cutting thickness $(h)$. When intermittent cutting is achieved, $h$ repetitively oscillating as analogous sine wave at ultrasonic frequency leads to reduction of average value of instantaneous abrasive cutting thickness.

(2) Grinding forces can be significantly reduced (up to $65.6 \%$ of normal grinding force, up to $47.7 \%$ of tangential grinding force, and up to $42.2 \%$ of cross feed directional grinding force) by introducing ultrasonic vibration into micro end grinding of silica glass.

(3) Ultrasonic assistance gives rise to positive influences of the variation percentage of tangential grinding force with increase of grinding parameters, because of which larger depth of cut and feed rate can be adopted in micro end grinding of silica glass to improve material removal rate and machining efficiency.

(4) Intermittent cutting in micro grinding process achieved by introducing ultrasonic vibration leads to the reduction of abrasive cutting thickness and undeformed chip thickness. Therefore, comparing with CMEG, the ductile machining is easier to achieve; meantime, the surface quality is significantly improved in UAMEG.

(5) The aided ultrasonic vibration contributes much influence to the machining mechanism of micro end grinding, which has the nature of complexity and intricacy. Comprehensive models of grinding force, surface damage, and surface roughness need to be researched for further study on the mechanism of UAMEG. 


\section{Conflict of Interests}

The authors declare that there is no conflict of interests regarding the publication of this paper.

\section{Acknowledgments}

This work was supported by the Natural Science Foundation of Hebei Province of China (project nos.: E2012202088 and E2012202112) and Innovation Fund for Outstanding Youth of Hebei University of Technology (project no.: 2012011).

\section{References}

[1] T. Masuzawa, "State of the art of micromachining," CIRP Annals-Manufacturing Technology, vol. 49, no. 2, pp. 473-488, 2000.

[2] E. Brinksmeier, Y. Mutlugünes, F. Klocke, J. C. Aurich, P. Shore, and H. Ohmori, "Ultra-precision grinding," CIRP Annals: Manufacturing Technology, vol. 59, no. 2, pp. 652-671, 2010.

[3] K. Ramesh, H. Huang, L. Yin, and J. Zhao, "Microgrinding of deep micro grooves with high table reversal speed," International Journal of Machine Tools and Manufacture, vol. 44, no. 1, pp. 39-49, 2004.

[4] A. Perveen, M. P. Jahan, M. Rahman, and Y. S. Wong, "A study on microgrinding of brittle and difficult-to-cut glasses using on-machine fabricated poly crystalline diamond (PCD) tool," Journal of Materials Processing Technology, vol. 212, no. 3, pp. 580-593, 2012.

[5] D. Dornfeld, S. Min, and Y. Takeuchi, "Recent advances in mechanical micromachining," CIRP Annals-Manufacturing Technology, vol. 55, no. 2, pp. 745-768, 2006.

[6] J. Feng, B. S. Kim, A. Shih, and J. Ni, "Tool wear monitoring for micro-end grinding of ceramic materials," Journal of Materials Processing Technology, vol. 209, no. 11, pp. 5110-5116, 2009.

[7] B. Lawn and R. Wilshaw, "Indentation fracture: principles and applications," Journal of Materials Science, vol. 10, no. 6, pp. 1049-1081, 1975.

[8] B. R. Lawn and D. B. Marshall, "Hardness, toughness, and brittleness: an indentation analysis," Journal of the American Ceramic Society, vol. 62, no. 7-8, pp. 347-350, 1979.

[9] M. Arif, M. Rahman, and W. Yoke San, "Analytical model to determine the critical feed per edge for ductilebrittle transition in milling process of brittle materials," International Journal of Machine Tools and Manufacture, vol. 51, no. 3, pp. 170-181, 2011.

[10] K. Junichiro, Precision Machiningand Vibration Assisted Cutting, Base and Application, China Machine Press, Beijing, China, 1982.

[11] T. Tawakoli, B. Azarhoushang, and M. Rabiey, "Ultrasonic assisted dry grinding of 42CrMo4," The International Journal of Advanced Manufacturing Technology, vol. 42, no. 9-10, pp. 883891, 2009.

[12] T. Tawakoli and B. Azarhoushang, "Influence of ultrasonic vibrations on dry grinding of soft steel," International Journal of Machine Tools and Manufacture, vol. 48, no. 14, pp. 1585-1591, 2008.

[13] J. Akbari, H. Borzoie, and M. H. Mamduhi, "Study on ultrasonic vibration effects on grinding process of alumina ceramic $\left(\mathrm{Al}_{2} \mathrm{O}_{3}\right)$," World Academy of Science, Engineering and Technology, vol. 41, pp. 785-789, 2008.
[14] D. B. Marshall and B. R. Lawn, "Indentation of brittle materials," in Microindentation Techniques in Materials Science and Engineering, P. J. Blau and B. R. Lawn, Eds., pp. 26-46, American Society for Testing and Materials, Philadelphia, Pa, USA, 1986.

[15] T. G. Bifano and S. C. Fawcett, "Specific grinding energy as an in-process control variable for ductile-regime grinding," Precision Engineering, vol. 13, no. 4, pp. 256-262, 1991. 

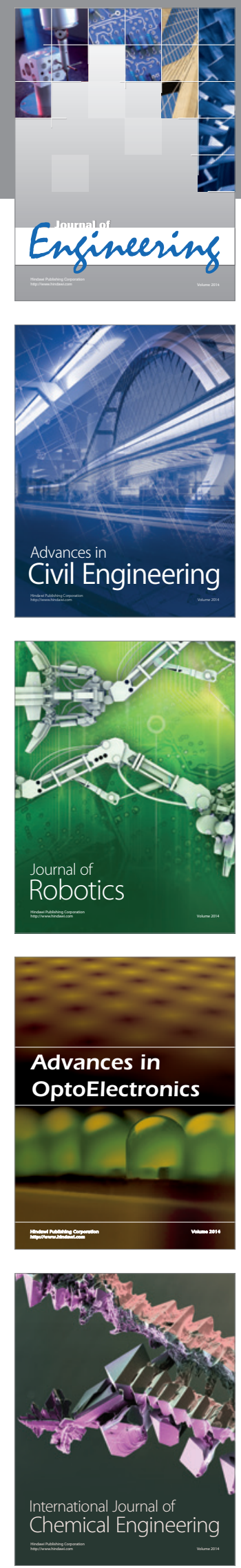

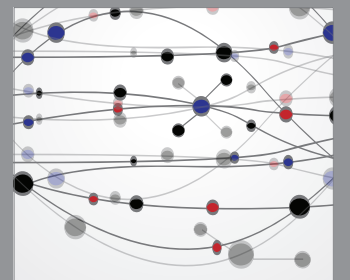

The Scientific World Journal
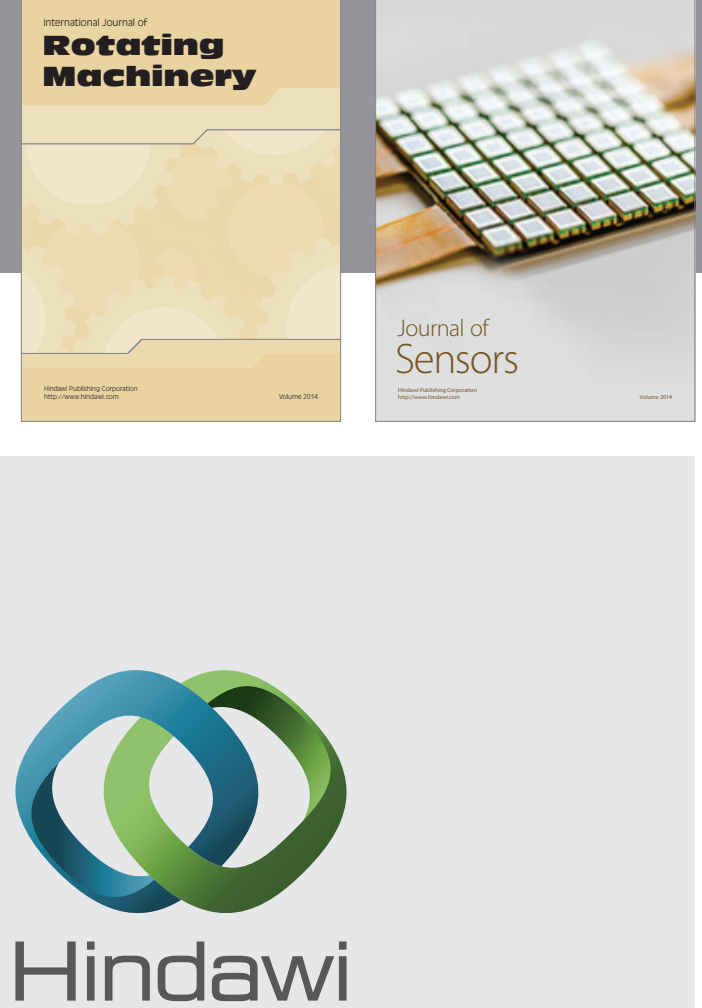

Submit your manuscripts at http://www.hindawi.com
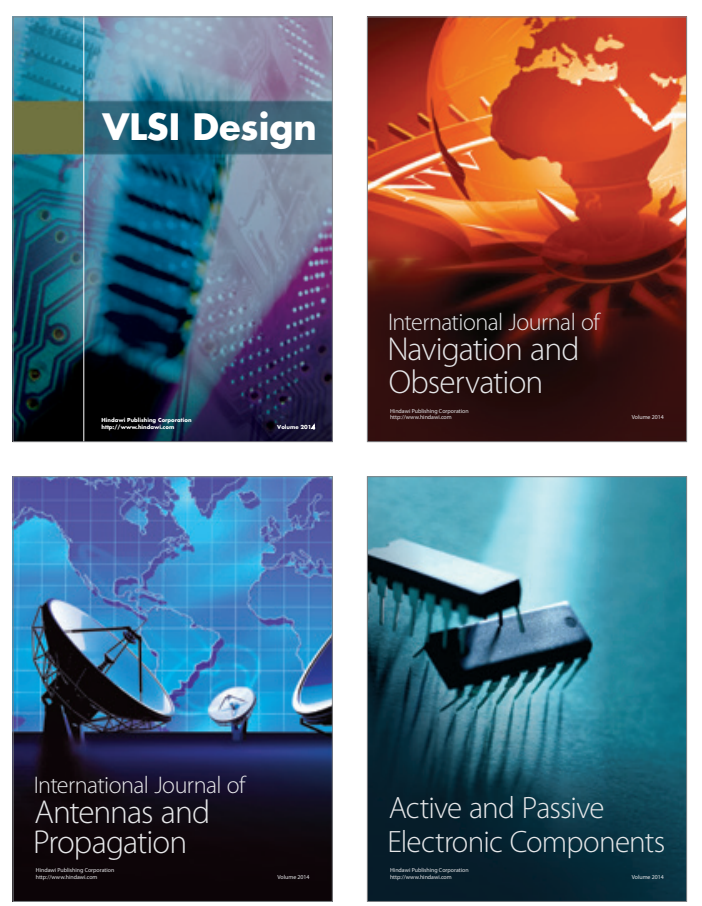
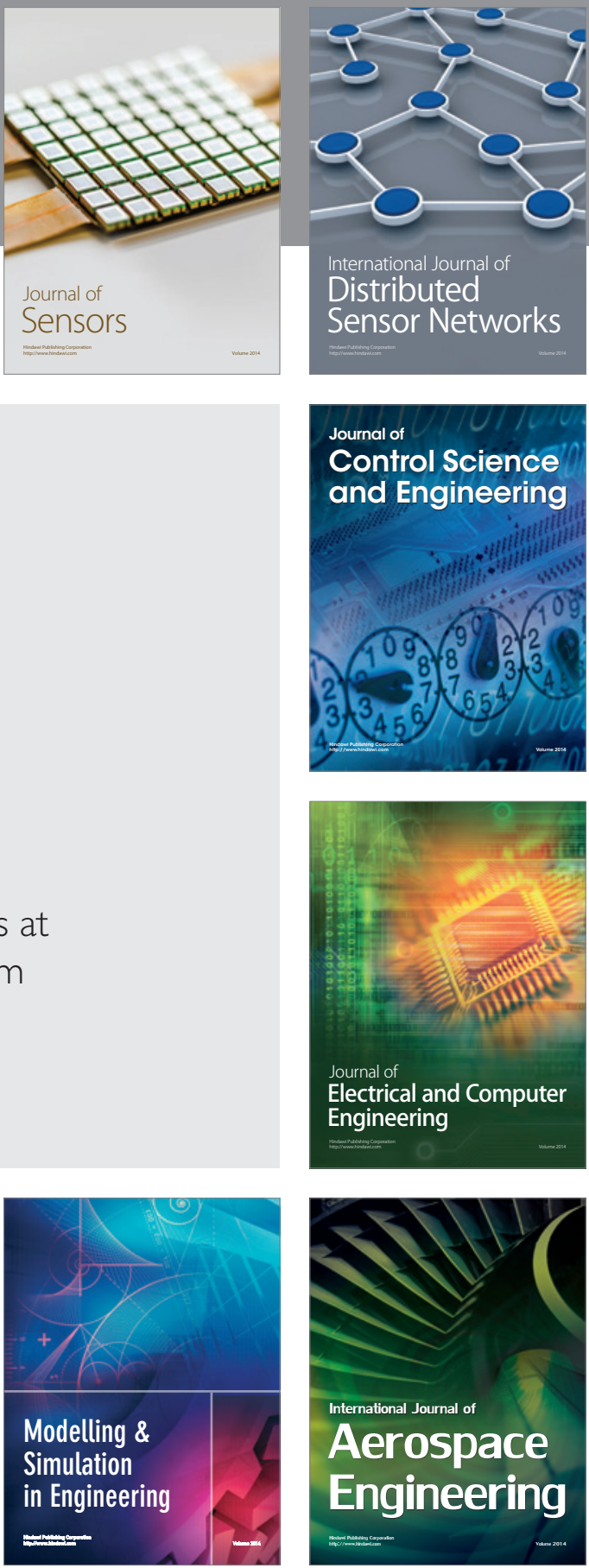

Journal of

Control Science

and Engineering
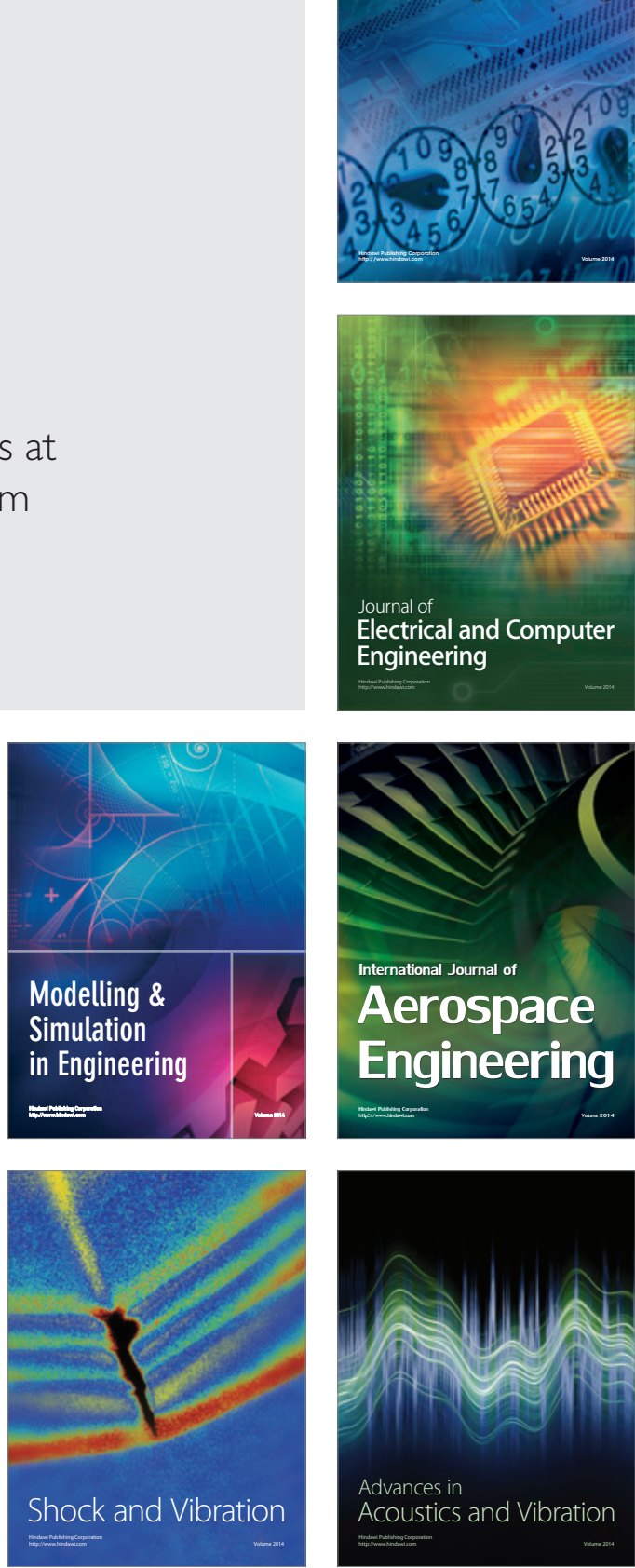